\author{
Bohdan RUSYN ${ }^{1,2}$ \\ Natalia HRABOVSKA ${ }^{1}$ \\ Vitali IVANIUK ${ }^{1}$ \\ Jura LYSAK ${ }^{1}$ \\ Jeremi VARETSKY ${ }^{1}$
}

\title{
INFORMATION TECHNOLOGY OF THE PITTING THREE-DIMENSIONAL RECONSTRUCTION BY HALFTONE IMAGES
}

The new information technology of determining the pitting depth by analyzing metallographic image from using Lambert's model of light reflection is proposed. Parameters of the model defined by the known fixed positions of the light source, using shading and unchanging position of the receiver. The reconstruction of threedimensional pitting structure carried out in two stages. At the first step a vertical pitting section reconstructed in the form of vertical derivative of the normal vector, and evaluation of the pitting section depth found by accumulation of integral vertical derivative of the pitting normal vector from one of the edges. At the second step based on the approximation of the vertical pitting section, created artificial pitting model. An example of the practical application of the developed information technology for $3 \mathrm{D}$ surface reconstruction of real pitting is shown.

\section{ZASTOSOWANIE TECHNOLOGII INFORMATYCZNEJ DO TRÓJWYMIAROWEJ REKONSTRUKCJI PITTINGÓW PRZEZ ANALIZĘ}

W artykule zastosowano technologię informatyczną do określania głębokości wżerów (pittingów). Analizowano obraz metalograficzny używając Lamber'towskiego modelu odbicia światła. Parametry modelu określono przy znanych stałych położeniach źródła światła za pomocą cieniowania i niezmiennego położenia odbiornika. Przebudowę struktury trójwymiarowej wżerów przeprowadzona w dwóch etapach. W pierwszym etapie w przekroju pionowym wżeru określono pochodną wektora normalnego i oceniono głębokości sekcji wżeru. W drugim etapie na podstawie zbliżenia pionowej sekcji wżeru zbudowano model. Przedstawiono praktyczne zastosowanie opracowanej technologii informatycznej do rekonstrukcji powierzchni 3D rzeczywistego wżeru.

\section{INTRODUCTION}

There are a series of image processing systems (IPS) that are used for solving applied problems of nondestructive testing condition of structural elements affected by corrosion defects and including pittings. The peculiarity of IPS is that they use a variety of information technology (IT) [1-7]. So one of the field of research of defects resistance on pipeline is based on a non automatized visual image processing [8]. This IT is quite time-consuming and usually gives information about the defects character only in the image area. IPS using automated IT of three-dimensional reconstruction in the case of non-destructive control of defects resistance on pipeline elements make it possible to significantly increase the efficiency of operators with images and obtain more information about the objects of studied scene, including their three-dimensional structure and to estimate the defect depth, according to two-dimensional images. Such systems with analysis of three-dimensional surface structure should include a light source and a video camera. The study sample illuminate by incoherent light source. The reflected light from the surface fixed by a camera and transmitted to a computer for analysis. During recovering of three-dimensional surface structure of objects from which the reflected light permeate in videocamera, consider as diffuse and specular reflection [9, 10]. Since objects with diffuse reflection of light have the same light intensity in all directions of observation, so consider theirs 3D reconstruction. Analyzed only areas covered with corrosion products. Among the information technology of three-dimensional reconstruction (which include 3D reconstruction by stereo $[3,7]$ and the reflection model $[6,11-13]$ ) perspective seems recovery form pitting surface by one half-tone image [13] from the adaptability of implementing IT.

\footnotetext{
${ }^{1}$ Karpenko Physico- Mechanical Institute of NAS of Ukraine, Ukraine

${ }^{2}$ Kazimierz Pulaski University of Technology and Humanities in Radom, Poland
} 
The purpose of this study is developing a new IT nondestructive control of surface condition which affected by pitting corrosion, especially three-dimensional defect reconstruction and evaluation of its depth by results of analysis of surface digital images based on two-stage procedure.

\section{Illumination image model}

For diffuse reflection model (monochromatic image) reflection intensity of the point on the surface luminated by one light source is determines the equation [9]:

$$
I_{\lambda}=I_{a}+I_{p \lambda} k_{d}(N \cdot L),
$$

where: $I_{a}$ - the intensity of the scattered light, $I_{p \lambda}$ - the intensity of the light source, $k_{d}-$ diffusion coefficient, which sets the level of diffuse reflection investigated point on the surface, $L=\left(L_{x}, L_{y}, L_{z}\right)-$ direction of the light source, $N$ - unitary vector normal to the surface $F(x, y, z)=0$ in the study point $M=(x, y, z)$.

Accept that the reconstruction performed when the surface is given explicitly $z=f(x, z)$. Then the normal vector takes values $N=\{-p d,-q d, d\}$, where $d=\left(p^{2}+q^{2}+1\right)^{-\frac{1}{2}}$, and $p=\frac{\partial z}{\partial x}, \quad p=\frac{\partial z}{\partial y}-$ surface slope in a neighborhood of point [14]. Videography performed so that the distance from the light source to the object was be much greater than the linear dimensions of the investigated surface.

\section{Two-stage information technology}

To the pitting depth reconstruction estimation in work is proposed two-stage IT. In the first stage we find pitting section $\mathrm{z}$ in the most informative area where it passes through the maximum depth. In the second stage based on the obtained evaluation of the resulting cross section $z$, we define full-scale evaluation of 3D pitting surface by approximation surface of sphere segments.

\section{Stage 1}

Consider the first stage IT. To determine the pitting depth we will choose its vertical section. Define the parameters $p, q, k_{d}$ and $I_{a}$ of model (1) for case $L=(0, \cos \varphi, \sin \varphi)$. To calculate the background intensity $I_{a}$ used shaded pitting surface point in which $I_{a}=I_{\lambda}\left(x_{a}, y_{a}\right)$. To determine the diffusion coefficient we will use a point defect in which a $q\left(x_{0}, y_{0}\right)=p\left(x_{0}, y_{0}\right)=0$. Then from the expression (1) follow $\imath=I_{p \lambda} k_{d}=\left(I_{0}-I_{a}\right) / \sin \varphi$, where $I_{0}=I_{\lambda}\left(x_{0}, y_{0}\right)$. To ensure simplification reflection model, which is to reduce the reconstruction error caused by fluctuations horizontal pitting depth is proposed to conduct low-frequency image filtering in the horizontal direction [13]. In the filtered segment of the image $\bar{I} \mathrm{~m}_{\Delta P}$, which will allocated the vertical pitting cross section, operates simplifying assumptions: pitting depth $z(x, z)$ is constant on the horizontal segment $\left[x_{o}, x_{o}+d\right]$, which can be formally represented as $p(x, y)=0$, where $x \in\left[x_{o}, x_{o}+d\right]$. Using this in the model (1), and identified background value $I_{a}$ and weighted diffusion coefficient $l$, we obtain quadratic equation $\quad a q^{2}+b q+c=0, \quad$ where $\quad a=\operatorname{ctg}^{2} \varphi-\xi ; \quad b=-2 \operatorname{ctg} \varphi ; \quad c=1-\xi$; $\xi=\left(I_{\lambda}(x, y)-I_{a}\right)^{2} \cdot\left(I_{\lambda O}-I_{a}\right)^{-2}$, which allows us to calculate its roots $q_{1,2}$ by program. Root array $q_{1}(y)$ is a reconstruction of the vertical derivative. In the filtered area the reconstruction of the pitting surface section perform by integral accumulation of vertical derivative starting from the defects bottom.

\section{Stage 2}

The second IT stage consist in the following four algorithms: creating of the artificial pitting model; optimal shifting of the artificial model in trhe horizontal direction; optimal compression of the left (right) segment of artificial model with the parameter $l_{\text {opt }}\left(r_{\text {opt }}\right)$. Consider each of these algorithms.

The algorithm of artificial model. The pitting surface formed by rotating its vertical section $z=f(y)=f\left(x_{\max }, y\right)$ respectively the vertical axis $O z$, which passes through the maximal depth point $\left(\mathrm{x}_{\max }, y_{\text {max }}\right)$ with the same form $z=f(\rho)$, where $\rho=\sqrt{\left(x_{1}-s\right)^{2} \eta^{-2}+\left(y-y_{\text {max }}\right)^{2}}$, there $x_{1}=x-\mathrm{x}_{\text {max }}, S-$ shift in the direction $x_{1}, \eta$-compression to the vertical line passing through the point $\left(\mathrm{x}_{\max }-s, y_{\max }\right)$ and $\eta \in\{l, r\}$, where compression with $l(r)$ performed for points $(x, y)$ such that $\mathrm{x}<\mathrm{x}_{\max }-s \quad\left(\mathrm{x}>\mathrm{x}_{\max }-s\right)$. To simplify the software implementation of this algorithm shift pitting section $z=f(y)$, where $y \in\left[-y_{s}, y_{s}\right]$ modeled vertical 
crack $C r_{x}$ and horizontal $C r_{y}$ and formed surface $\breve{z}=C r_{y}+C r_{x}+z_{\max }$. Points $(x, y)$ in which $\breve{z}(x, y)>0$, eliminated from consideration and replaced by plane $\breve{z}(x, y)=0$.

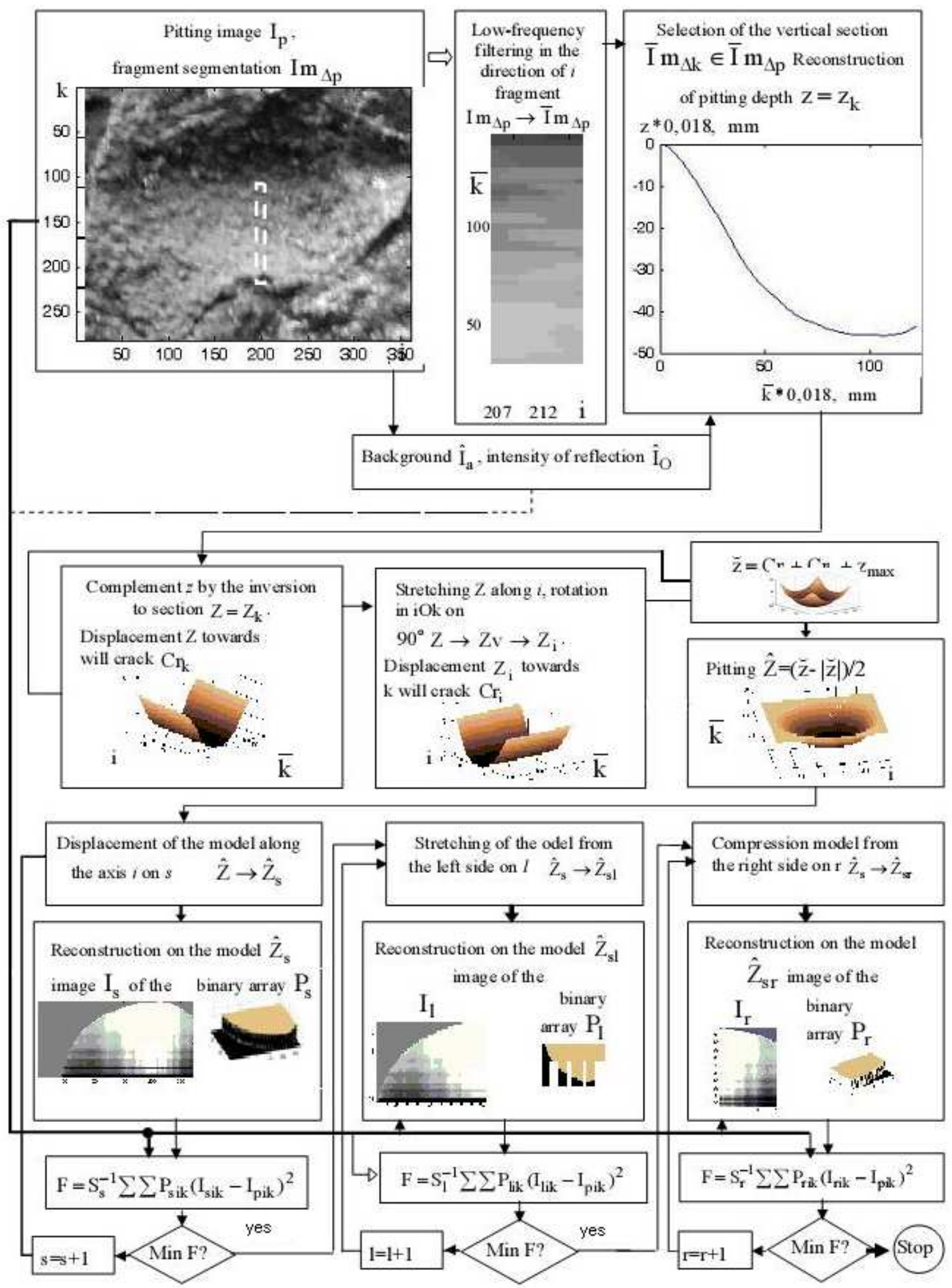

Fig. 1. IT assessment of the pitting depth for material surface halftone image 
The optimal shift algorithm is as follows. We fix the parameter $\eta$. Resorting to experimental background evaluations $\hat{I}_{a}$ and the intensity of reflection $\hat{I}_{\lambda 0}$ for diffuse reflection model (1), where the components of the normal vector $p, q$ are calculated by the shifted pitting model $z(s)$, we synthesize the artificial image of pitting model $I_{s}$. Determine the absolute error of assessment $\Delta I=I_{p}-I_{s}$, where $I_{p}-$ the real pitting image. By integral accumulation of square $\Delta I$ on all points belonging to pitting, determine the quadratic form $F_{s}$. To the specification of the model $z(s)$ looking the minimum of quadratic form $F_{s}$, which is calculated from the parameter $s=\mathrm{s}_{\text {opt }}$. Found parameter $\mathrm{s}_{o p t}$ used in the adaptive correction in the segments of artificial model $z=f_{2}\left(\mathrm{~s}_{o p t}, l\right)$ and $z=f_{2}\left(\mathrm{~s}_{o p t}, r\right)$. To clarify the quadratic forms the application of selective individual functions $P_{g}$, where $g$ takes value $s$, or $l$, or $r$, and take into account the spatial selection $F_{g}=S_{g}^{-1} \sum_{i} \sum_{k} P_{g i k}\left(I_{p i k}-I_{g i k}\right)_{g i k}^{2}$, where $I_{g}$ artificial image pitting model, $S_{g}$ - area of the function single values $P_{g}$. Spatial selection are two types. One of these laid in the algorithms structure of IT and the other is used for the extraction of quadratic forms of artifacts points (the pitting form is damaged and radically different from the common).

Practical application of the developed IT estimation of pitting depth by a material surface half-tone image (fig.1).

For $3 \mathrm{D}$ reconstruction using video information (direction of illumination light source $L=(0 ; 0,88 ; 0,47)$, angle $\varphi=0,49$ ) about pitting, placed on the tube of steel 17HS. On the pitting image $I_{p}$ horizontal disposition reconstruction fragment $I \mathrm{~m}_{\Delta p}$ is visually outlined white dashed line and the results of its low-frequency filtering in the horizontal direction $i$ with zoom represented as a fragment $\bar{I} \mathrm{~m}_{\Delta p}$. The vertical segment (one-dimensional array of source data $\bar{I} \mathrm{~m}_{\Delta k}=\bar{I}_{214, \bar{k}}$ ) belonging to array $\bar{I} \mathrm{~m}_{\Delta p}$, mutual with the experimentally determined estimates of background $\hat{I}_{a}$ and the intensity of reflection $\hat{I}_{0}$ and angle $\varphi$ was used to calculate the values of an array of vertical derivative $q_{1}$. Comparing on the image $I_{p}$ the size of objects in millimeters (white stripe with millimeter dashes) and pixels is estimated the dicretization step $\Delta y=\Delta x$. Be integral accumulation vertical derivative $q_{1}$ with the stem $\Delta y$ were calculated pitting depth estimates array $z=z_{\bar{k}}$, where $\bar{k} \in[1,122]$ and defined maximal pitting depth $z_{\max }$.

Simulate the total pitting cross section $Z=Z_{\bar{k}}$, where $\bar{k} \in[1,205]$. From examination of image $I_{p}$ shows that horizontal pitting size pitinha is bigger compared to the vertical direction.

To eliminate the asymmetry of the left side of the pitting by the array $Z$ interpolation in the range $\bar{k} \in[1,103]$ received array $Z v=Z v_{k}$, where $k \in[1,271]$.

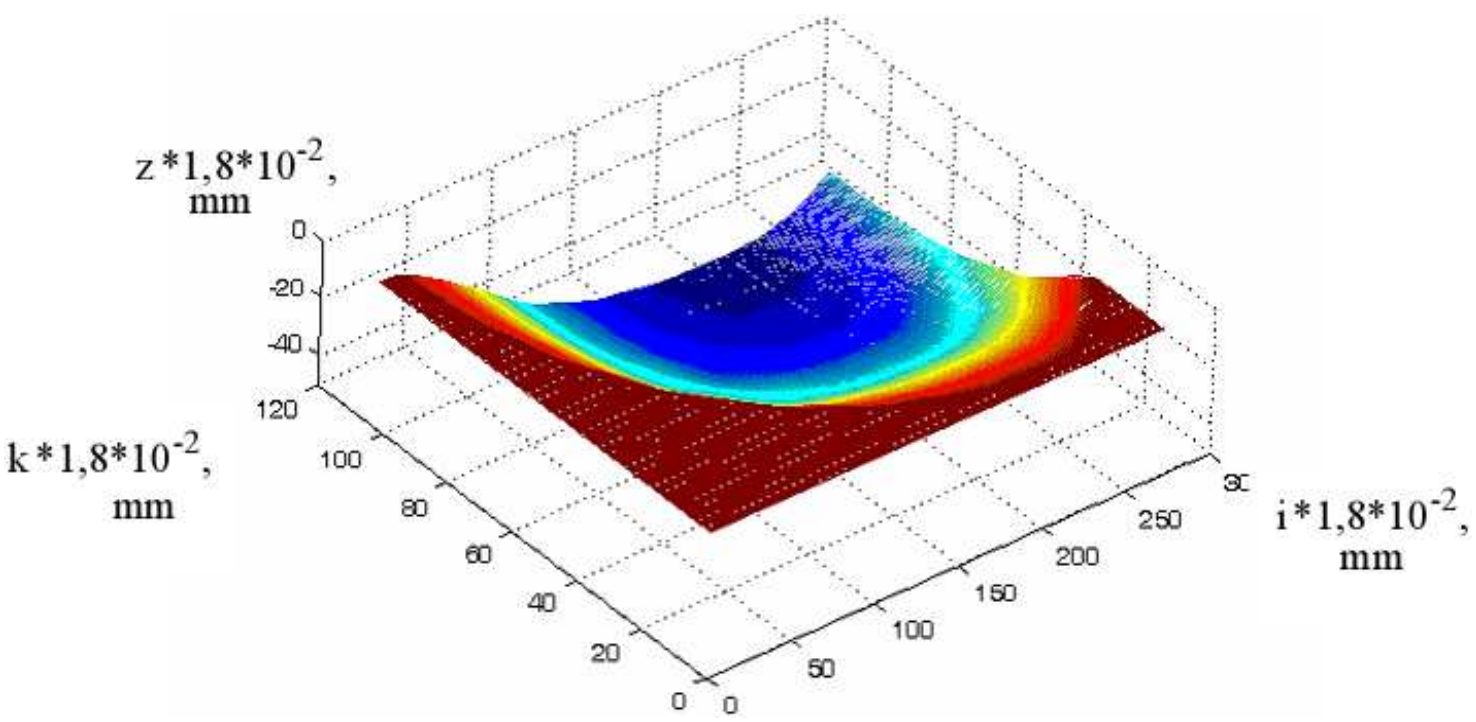

Fig. 2. The reconstructed pitting model 
To the correction of the artificial pitting model used shift of this model in the direction $i$ and operation of segments stretching of pitting model and compression. The program which implements the optimal shift performed as long as the quadratic form $F$ not minimized by $s_{\text {opt }}$. The program which implements the optimal compression or stretching of left (right) segment of artificial model performed as long as the quadratic form $F$ not minimized by $l_{\text {opt }}\left(\left(r_{\text {opt }}\right)\right.$.

Reconstruction result of real pitting dislocated on a real pipeline is shown in figure 2.

\section{CONCLUSIONS}

In this paper we consider the problem of three-dimensional reconstruction of the pitting surface for half-tone images of the surface. To solve this problem the two-stage procedure defect reconstruction is proposed. In the first step the vertical pitting cross-section is reconstructed in the form of vertical derivative of normal vector and evaluation of the pitting depth found by integral accumulation of vertical derivative of the vector normal from one of the edges. The vertical derivative reconstructed based on Lambert's reflectance light model in which uses the information about the backlight intensity, illumination intensity in the center of the pitting, illumination intensity of the pitting vertical section points.

In the second step based on the approximation of the vertical pitting section constructed artificial defects model and found its optimal shift in the horizontal direction, also calculated the optimal stretching of the left segment and compression of the right segment of artificial model. Optimization of its parameters is conducted by comparing the artificially created image parametrically dependent model and the real pitting image.

Experimentally verified workability of the proposed information technology for real pittings. The practical importance of the work is that developed information technology we can implement in the standard system processing.

\section{BIBLIOGRAFIA}

[1] Yoshizawa, T.: Handbook of Optical Metrology -principle and applications-/ CRC Press, New York 2009.

[2] S. Zhang, "High-resolution 3-D profilometry with binary phase-shifting methods," Appl. Opt.50(12), 2011 P.1753-1757.

[3] Richard Szeliski: Computer Vision: Algorithms and Applications. Springer, New York, 2010.

[4] Q. Zhang, X. Su, L. Xiang, and X. Sun, "3-D shape measurement based on complementary gray-code light," Opt. Lasers Eng., vol. 50, 2012, p.574-579.

[5] Song Zhang Flexible 3-D shape measurement with projector defocusing: Extended measurement range / Optics Letters, Optical Society of America April 1, Vol. 35, No. 7, 2010.

[6] Woodham R.J.: Photometric method for determining surface orientation from multiple images // Optical Engineering. 1980. - 19(1). - P.139-144.

[7] Synyavskyy A.T., Rusyn B.P.: The implementation of the surface microstructure reconstruction method by stereo images from optical cameras // Radioelectronics and Informatics. 2005.- № 2.- C.112-118 (in Ukrainian).

[8] A. Ya. Krasovs'kyy: Evaluation of residual life of the pipeline damaged by stress corrosion / A. Ya. Krasovs'kyy, I. V. Orynyak, I. V. Lokhman // Pipeline transport. - 2011. - № 2 (68). - C. 18-21 (in Ukrainian).

[9] J. H. Lambert: Photometria, sive de Mensura et gradibus luminis, colorum et umbrae / sumptibus viduae E. Klett, 1760.

[10] J. Foley, S. Feiner, J. Hughes, and A. Van Dam: Computer Graphics: Principles and Practice, AddisonWesley. - 1997- 1175 P.

[11] Spence A.D., Chantler M.J.: Optimal illumination for three-image photometric stereo acquisition of texture // In Texture 2003: Proceedings of the 3rd international workshop on texture analysis and synthesis. P.89-94, 2003.

[12] Rusyn B.P.: Non-destructive control of surfaces state affected by corrosion pittings / B.P. Rusyn, N.P. Anufriyeva, N.R. Hrabovs'ka, V.H. Ivanyuk // Phys-Chem. Mech. of Mat. - 2013 -№4 -C. 90-96 (in Ukrainian).

[13] Rusyn B.P.: Assessment of defect depth on weld by 2D material surface image / B.P. Rusyn, N.P. Anufriyeva, V.H. Ivanyuk, O.V. Kapshiy, V.V. Korniy, R.M. Yurkevych // Radioelectronics and Informatics. 2011. -№1-C.75-82 (in Ukrainian).

[14] V. I. Smirnov: A Course of Higher Mathematics, Vol. 1, Nauka, Moscow (1967) (in Russian). 